\title{
HIV Exposure through Heterosexual Contacts: Analysis of Demographic, Behavioral and Structural Risk Factors among Black Men in Ottawa and Windsor, Ontario
}

\author{
Francisca I. Omorodion, Egbe B. Etowa, Jelani Kerr, Bishwajit Ghose, and Josephine Etowa
}

\section{ABSTRACT}

We determined the association of demographic, behavioral, and structural factors with risk of HIV exposure through heterosexual contact among Black men in Ottawa $(n=210)$ and Windsor $(n=156)$, Ontario. We applied hierarchical linear regression model in the analysis. Mean HIV exposure risk scores were Windsor (12.08 \pm 8.42$)$ and Ottawa (17.16 \pm 11.80$)$ in Ottawa (Scale $=48$ ). Age, marriage, employment, masculinity, and condom attitudes were statistically significant ( $p<0.05)$. Age groups (15-29 years and 40-49 years), traditional masculine ideology, and negative condom attitudes associated with increased risk of HIV exposure by heterosexual contact. Marriage and fulltime employment associated with reduced risk of exposure the ACB heterosexual men.

Keywords: behavior, Black men, heterosexuality, HIV risk factors.

\section{INTRODUCTION}

Exposure through heterosexual contact is the second leading cause of new HIV cases in Canada [1]. Besides biological, genetic, and immunological considerations; behavioral risk factors also influence infectiousness and susceptibility to HIV risk. Behavioral risks factors transcend the nature of sexual act (anal, vaginal or oral; insertive or receptive; protected or unprotected) to include several cofactors, such as the type of sexual partnership [2] and concurrency of sexual partners [3]-[6]. In addition, unprotected multiple sexual contacts have also been identified as important HIV risk factor [7], [8]

The accuracy of the measurement of HIV risk is often contested, as it may be dependent on several factors, some of which are often not captured in measuring the HIV risk of an individual. However, the conceptual view of HIV risk in this
Submitted : February 28, 2021

Published : April 23, 2021

ISSN: $2593-8339$

DOI: 10.24018 /ejmed.2021.3.2.747

\section{F. I. Omorodion}

Department of Sociology,

Anthropology and Criminology;

University of Windsor, Ontario,

Canada.

(e-mail: omorodif@ uwindsor.ca)

E. B. Etowa*

Department of Sociology,

Anthropology and Criminology;

University of Windsor, Ontario, Canada.

(e-mail: eetowa@uwindsor.ca)

J. Kerr

Department of Health Promotion and Behavioral Sciences, University of Louisville, Kentucky, USA.

(e-mail: j.kerr@1ouisville.edu)

B. Ghose

School of Nursing, University of Ottawa, Ontario, Canada.

(e-mail: bghose@uottawa.ca)

J. Etowa

School of Nursing, University of Ottawa, Ontario, Canada.

(e-mail: jetowa@uottawa.ca)

*Corresponding Author

paper is that the cumulative probability of HIV transmission over many acts during single or multiple sexual partnership(s), is dependent on the infectiousness of the HIVinfected sexual partner(s) and the susceptibility of the HIVuninfected sexual partner(s) [9]. For example, a study showed that transmission via heterosexual exposure start to occur at values of 1500 copies of HIV-1 RNA per milliliter [10]. Furthermore, although heterosexual contact is estimated to account for HIV transmission risk of $0.04 \%$ to $0.08 \%$ per act in developed countries [9], the cumulative risk can be far higher depending on the associated behavioral risk factors. The notion of cumulative risk is based on the premise that relatively small risks add up to a high lifetime risk of HIV transmission [11]. Although the chance of acquiring HIV in an insertive unprotected sexual intercourse with an HIV infected female partner may be as small $0.04 \%$, several repeated sexual contact with this partner is likely to increase 
the risk of transmission to a very large extent. Because of the difficulty and the often-contested reliability of the risk of HIV transmission measures, this study rather estimates the likelihood of exposure to HIV through unprotected multiple sexual partnerships.

Canadian HIV surveillance report bears credibility to the preceding view by noting that heterosexual contact $(32.3 \%)$ now tops second after gay, bisexual and men who have sex with men (gbMSM [41.4\%]) as the mode of HIV transmission among all reported exposure categories in 2018 [12]. The increase of HIV transmission among heterosexual subpopulations has been attributed to masculinity [13], [14], low use and unfavorable attitudes towards condoms [15], less HIV testing [16], and engaging in extra marital sex with multiple core very high risk women [17]. Structural factors including social, economic, cultural and immigration experience [18], education [19], employment status [20], and racial inequalities [21] have been significantly associated with HIV risk [22], [23]. Although HIV transmission through heterosexual sex has been attributed to populations from HIV endemic countries, recent data show increases in new cases among persons born in Canada [12], and those from HIV endemic countries contract HIV after their arrival in developed countries [24], [25]. The latter occurs because newcomers believe that their host country is free or safe from HIV infection and/or there is no HIV in the host countries [26]. Yet, sexual behavior of Black populations is not remarkably different from those of other races [27], but the risk of HIV infection can be much higher in Black communities due to systemic, economic and health factors aside sexual behavior. Globally, socioeconomic factors further compound HIV risk among Black populations, because of low availability and accessibility to formal job sectors [22], challenged neighborhoods [5], [28], and everyday experiences of discrimination and racism [29]. Additionally, psychosocial attributes such as lack of appropriate knowledge or wrong perception of HIV are enablers of HIV risk among heterosexual ACB men [22]. Despite increased emphasis of economic hardship as factor for HIV risk [30]-[32], in certain situations men with comparatively higher income and increased leisure time were more vulnerable to HIV. This was attributed to increase spending on alcohol intake and multiple sexual encounters [33].

To address these disproportionate HIV risks, and the rates of HIV infection in general, some research and interventions were initiated. The National HIV/AIDS Strategy for Black Canadian, African and Caribbean Communities project was a research initiative funded by PHAC to identify strategies to address the disproportionate HIV vulnerability in the Black community. There is also the Federal Initiative that addresses HIV/AIDS in Canada, and Canada's Framework for Action, Reducing the Health Impact of Sexually Transmitted and Blood-Borne Infections in Canada by 2030. But more concerted effort is required to address factors of HIV risk among the Black community. In the past, HIV prevention has focused on behavioral change through traditional and public health messaging emphasizing HIV risk associated with multiple sex partnerships. Yet, the risk of HIV transmission is not solely dependent on one's own sexual behavior, but on multifaceted factors including community and societal contexts, such as where they live [34]. In this paper, we explore and compare the correlates of HIV risk among selfidentified heterosexual African, Caribbean, and Black Canadian (ACB) men living in Windsor and Ottawa. The analyses aimed to highlight areas of intervention in addressing local nuances of HIV vulnerability among heterosexual ACB men.

\section{METHODS}

\section{A. Sampling and Recruitment}

The present paper draws from a broader weSpeak study in four Ontarian cities comprising Windsor, London, Toronto, and Ottawa using mixed methods research design on a sample of self-identified heterosexual ACB men [35]. Based on the quantitative data from Ottawa $(n=210)$, and Windsor $(n=156)$, this analysis examines the correlates of HIV exposure among a total of 366 self-identified heterosexual ACB men. Data were drawn from three key measures in the survey questionnaire, namely: i) Sociodemographic background, which asked participants to indicate their age, country of birth, residency status, immigration history, relationship status, living arrangement, level of education, self-rated health status, employment, and income, amongst others; ii) Health status characteristics, including a measure of difficulty in accessing healthcare; and iii) Measures of crucial attitudinal, psychological, and structural correlates or characteristics, based on pro-community attitude, traditional masculinity, attitudes to condom use, HIV knowledge and behavior towards HIV testing, amongst others.

We provided descriptive statistics (frequencies and percentages) of demographics variables (age, marital status, educational attainment, employment status, religion, etc.). We also described HIV risk measures including frequencies of condom use with regular versus casual sex partners, and number of regular versus casual sex relationships.

\section{B. Measures of Variables}

The dependent variable, "risk of HIV exposure through heterosexual contact" was adapted from four items on the survey questionnaire. One question asked: "In the last 12 months, how many regular female sex partners have you had penetrative vaginal or anal sex with?" The second item was: "In the last 12 months, how often did you use condoms with your casual female sex" partner(s)?" Response categories were rated as: none $=0$; one partner $=1$; two partners $=2$; three partners $=3 ; 4$ or 5 partners $=4 ; 6$ to 10 partners $=5$; more than ten partners $=6$. The other two questions were about the frequency of condom use with sex partners, which asked: "In the last 12 months, how often did you use condom with your regular female sex partner(s)?" And "In the last 12 months, how often did you use condom with your casual female sex partner(s)". Because we were interested in measuring the HIV risks for unprotected sex, we reverse coded the response categories as follows: never $=4$; sometimes $=3$; most of the times $=2$; always $=1$. A total of 48 points was attainable on the HIV exposure risk scale, and was estimated by (1):

$$
\mathrm{HR}=\mathrm{Cr} \mathrm{Nr}+\mathrm{Cc} \mathrm{Nc}
$$


where:

HR = HIV exposure risk score for a participant

$\mathrm{Cr}=$ rating for the participant's condom use with regular female sex partner in the last one year.

$\mathrm{Nr}=$ rating for the number of regular female sex partner in the last one year

$\mathrm{Cc}=$ rating for the participant's condom use with regular female sex partner in the last one year

$\mathrm{Nc}=$ rating for the number of casual female sex partner in the last one year.

We selected the independent variables based on their explanatory power, the model fitness and reduced error estimate. Measures of the two groups of independent variables (sociodemographic and structural and behavioral variables) are described.

\section{Socio-demographic Variables}

The sociodemographic variables were transformed to binary forms for ease of interpretation and because few responses from the multiple response categories were not sufficient to account for meaningful correlations. City of residence was coded as: 1 for Windsor, and 0 for Ottawa. Three age categories were selected as independent variables for the analysis. Age 15-29 years were assigned 1 and 0 for ages outside that category. Similarly, age 30-39years were coded 1 , while age not in the category were coded 0 . Also, age 40-49 years $=1$, Otherwise $=0$. Educational attainment was coded as follows: Completed high school or a higher education $=1$, primary school or some high school $=0$. Employment status was assigned 1 if it is full time employment or 0 if otherwise. Marital status was coded 1 if married and 0 otherwise. Religion was coded 1 for Christianity and 0 if otherwise.

We measured other independent variables: racism, proBlack community attitude, new masculinity, traditional masculinity, resilience, condom attitudes, and self-rated health. Two of these variables were dummy coded as binary. Racism was measured by a count of types of everyday racisms, with rating ranging from 1 to 5 , and 0 if none of the types of racism was experienced in the past year. Counts were based on any of the five types of everyday discrimination that the participants experienced due to their racial background, they include: i) being treated with less courtesy, ii) receiving poorer services, iii) people acting as if you are not smart, iv) people acting as if they are afraid of you, and v) being threatened or harassed. Other variables in this group were scaled variables with scores determined on validated psychometric scales. The validated psychometric scales included: Pro-community attitude as measured on adapted Social Capital Scale [36], with a 5-item Likert-scale that measures the heterosexual ACB men's perceptions of people in their community in terms of trust, community cohesion, and community support. Response was coded as: strongly disagree (1), disagree (2), neutral (3), agree (4), and strongly agree (5). The scale had a maximum of 25 points score, and its internal consistency was acceptable $(\alpha=0.81)$.

We measured traditional masculinity and the new masculinity using the Masculine Role Identity Scale [37], with 17 items of masculine attributes measured in terms of importance on a 5-point Likert-style scale from "not at all important" to "extremely important." Internal consistency was acceptable $(\alpha=0.84)$; higher scores on this measure indicated that traditional masculinity ideology informed an individual's role identity. A high score on the reversed coding of the scale indicates high new masculinity score. This scale was particularly developed for use with Black men, and it is the only non-pathology-based masculinity scale available. HIV knowledge was measured on a Demographic and Health Survey (DHS) scale, which was validated and consists of 18 items [38] that assess the respondents' knowledge about HIV Response options were: Agree, Disagree, and Do not know. The total score from the response scale served as a covariate in the multivariate analysis. The Resilience Scale for Adults [39] consists of 33 validated items that measure 5 dimensions of resilience: personal competence, social competence, family coherence, social support, and personal structure. Respondents rated items using a Likert-style format with gradations from 1 (strongly disagree) to 5 (strongly agree). The respective dimensions had Cronbach's alphas of 0.80 , $0.76,0.83,0.84$ and 0.77 [40]. Condom attitude was measured on The Condom Use Scale [41]. It consists of 10 items that measured condom use in 3 dimensions: sexual satisfaction, gender, and sexual interest. Respondents rated items using a 5-point Likert-style response format with gradations from 1 (strongly disagree) to 5 (strongly agree). Internal consistency was acceptable $(\alpha=0.89)$. High overall score on the scale indicates negative attitudes towards.

\section{Analytical Techniques}

After the preliminary descriptive statistics, we used three levels of analyses to study the associated factors of HIV risk among heterosexual ACB men. In the first level, we attempted the linear mixed model in a multilevel analysis to determine the effect of city-level variables on HIV risk. Once, we found no city level effect on HIV risk, we employed hierarchical linear regression model, which controlled for demographic factors in a first block and determined the association of structural and behavioral factors on HIV risk in the second block. Model 1 shows the block 1 (demographic) variables including age, marital status, educational attainment, employment status, and religion. Model 2 shows block 2 variables including age racism, proBlack community attitude, new masculinity, traditional masculinity, resilience, condom attitude, and self-rated health. The software for the analysis was the IBM SPSS Statistics 26.

Because HIV exposure risk (dependent variable) was transformed into a continuous variable, an independent variable with coefficient less than 0 shows a negative association with HIV risks but show positive correlation with HIV risks if it is greater than 0. Specifically, this study hypothesised that HIV risk among self-identified heterosexual ACB men is independently associated with difficulty accessing health care, pro-Black community attitude, traditional masculine identity, condom attitude HIV Knowledge and HIV testing behavior (at $\alpha=0.05$ ). Also, HIV exposure risk is independently associated demographic variables (at $\alpha=0.05$ ). Prior to the specific hypothesis of independent associations, the study hypothesized that, 1) structural and behavioral factors jointly accounted for variation in HIV risk; 2) demographic factors jointly contributed to significant changes in HIV risk among ACB 
men.

\section{RESULTS}

\section{A. Descriptive Statistics of Demographic Characteristics}

Table I presents descriptive statistics of sociodemographic attributes of participants included in the analysis, which comprises of $42.60 \% \quad(n=156)$ and $57.40 \% \quad(n=210)$ heterosexual ACB men in Windsor and Ottawa, respectively. A majority was within age range, 15-49 years. In Windsor, $43.59 \%(n=68)$ were in the age range of: $15-29$ years, and $20.51 \%(n=32)$ were in $30-39$ years of age, and those in category of $40-49$ years were $9.6 \% \quad(n=15)$. In Ottawa, $51.42 \%(n=108)$ were $15-29$ years old and $23.81 \%(n=50)$ were $30-39$ years of age, and $18.10 \%(n=38)$ were in the 40 49 years age category. Men who were aged 50 years or older were 26. $28 \%(n=41)$ in Windsor, and $6.67 \%(n=14)$ in Ottawa. Above $50 \%$ of the men in Windsor $(n=80,51.28 \%)$ and Ottawa $(n=115,54.76 \%)$ were single. About a third of the men in Windsor $(n=44,28.21 \%)$ and Ottawa $(n=60,28.57 \%)$ were married. A few others were in a relationship living together or not living together.

TABLE I: DESCRIPTIVE STATISTICS OF SOCIO-DEMOGRAPHIC CHARACTERISTICS OF PARTICIPANTS

\begin{tabular}{|c|c|c|}
\hline Variables & Windsor $\mathrm{n}(\%)$ & Ottawa n (\%) \\
\hline City of residence & $156(42.60)$ & $210(57.40)$ \\
\hline \multicolumn{3}{|l|}{ Age categories } \\
\hline $15-29$ years old & $68(43.59)$ & $108(51.42)$ \\
\hline 30-39 years old & $32(20.51)$ & $50(23.81)$ \\
\hline 40-49 years old & $15(9.62)$ & $38(18.10)$ \\
\hline 50 years or older & $41(26.28)$ & $14(6.67)$ \\
\hline Total valid responses & $156(100)$ & $210(100)$ \\
\hline \multicolumn{3}{|l|}{ Marital status } \\
\hline Single & $80(51.28)$ & $115(54.76)$ \\
\hline Married & $44(28.21)$ & $60(28.57)$ \\
\hline Others & $32(20.51)$ & $35(16.67)$ \\
\hline Total valid responses & $156(100)$ & $210(100)$ \\
\hline \multicolumn{3}{|l|}{ Education } \\
\hline No formal schooling & $1(0.65)$ & $4(1.95)$ \\
\hline Completed elementary school & $45(29.41)$ & $37(18.05)$ \\
\hline $\begin{array}{l}\text { Completed high school, } \\
\text { college, or vocational school }\end{array}$ & $46(30.07)$ & $89(43.41)$ \\
\hline Completed university & $58(37.91)$ & $72(35.12)$ \\
\hline Others (unspecified) & $1(0.65)$ & $1(0.49)$ \\
\hline Did not know & $0(0.00)$ & $1(0.49)$ \\
\hline Preferred not to answer & $2(1.31)$ & $1(0.49)$ \\
\hline Total valid responses & $153(100)$ & $205(100)$ \\
\hline \multicolumn{3}{|l|}{ Employment status } \\
\hline $\begin{array}{l}\text { Employed or Self-employed } \\
\text { (full time) }\end{array}$ & $92(58.97)$ & $120(61.22)$ \\
\hline $\begin{array}{l}\text { Employed or Self-employed } \\
\text { (part time) }\end{array}$ & 29 (18.59) & $33(16.84)$ \\
\hline $\begin{array}{l}\text { Unemployed and looking for } \\
\text { work }\end{array}$ & $12(7.69)$ & $18(9.18)$ \\
\hline A full or part time student & $23(14.74)$ & $25(12.76)$ \\
\hline Total valid responses & $156(100)$ & $197(100)$ \\
\hline \multicolumn{3}{|l|}{ Religion } \\
\hline None & $13(8.50)$ & $20(9.76)$ \\
\hline Muslim & $9(5.88)$ & $32(15.60)$ \\
\hline Christian & $124(81.05)$ & $132(64.39)$ \\
\hline Others & $3(1.96)$ & $9(4.40)$ \\
\hline Preferred not to answer & $4(2.61)$ & $9(4.39)$ \\
\hline Did not know & $0(0.00)$ & $3(1.46)$ \\
\hline Total valid responses & $153(100)$ & $205(100)$ \\
\hline
\end{tabular}

Most of the men had completed high school, college, or vocational education (Windsor, [n=46, 30.07\%]; Ottawa, $[\mathrm{n}=89,43.41 \%]$ ) or University (Windsor, [n=58, 37.91\%]; Ottawa, $[\mathrm{n}=72,35.12 \%])$. Majority of the men were on full time paid or self-employment in Windsor $(n=92,58.97 \%)$ and Ottawa $(n=120,61.22 \%)$. Christianity was the common religion in Windsor $(n=124,81.05 \%)$ and Ottawa $(n=132$, $64.39 \%$ ).

\section{B. Descriptive Statistics of the Outcome Variable, HIV Exposure Risk}

Table II compares statistics of HIV risk score for participants in Windsor and Ottawa. For, ease of presentation and interpretation, the HIV exposure risk scores were categorised into 1-5, 6-10, 11-15, 16-20, 21-25, 26-30, 31-35, 36-40, and 41-48 as shown on the table, while the Windsor and Ottawa columns presents percent of men with the various score categories. As indicated the benchmark score on exposure risk is 48 . Precisely, $42.31 \%(n=66)$ and $38.57 \%$ $(\mathrm{n}=81)$ of the men in Windsor and Ottawa, respectively had zero score on risk of HIV exposure via heterosexual contact of the men. In Windsor majority scored within 1-25 with $11.54 \%(\mathrm{n}=18)$ and $22.44 \%(\mathrm{n}=35)$ scoring $1-5$ and $6-10$, respectively. In Ottawa, the most frequent responses $(n=45$, $21.43 \%$ ) yielded HIV exposure risk scores of $6-10$ with most of the men with falling within exposure risk scores of 6-25. Average HIV exposure risk score was greater in Ottawa $(17.16 \pm 11.80)$ than in Windsor $(12.08 \pm 8.42)$.

TABLE II: HIV EXPOSURE RISK THROUGH HETEROSEXUAL CONTACT: SCORES CATEGORY BY PERCENT OF MEN

\begin{tabular}{ccc}
\hline \hline Score & Windsor n $(\%)$ & Ottawa n $(\%)$ \\
\hline None & $66(42.31)$ & $81(38.57)$ \\
$1-5$ & $18(11.54)$ & $7(3.33)$ \\
$6-10$ & $35(22.44)$ & $45(21.43)$ \\
$11-15$ & $8(5.13)$ & $18(8.57)$ \\
$16-20$ & $10(6.41)$ & $18(8.57)$ \\
$21-25$ & $15(9.62)$ & $16(7.62)$ \\
$26-30$ & $2(1.28)$ & $7(3.33)$ \\
$31-35$ & $0(0.00)$ & $2(0.95)$ \\
$36-40$ & $2(1.28)$ & $7(3.33)$ \\
$41-45$ & $0(0.00)$ & $7(3.33)$ \\
$46-48$ & $0(0.00)$ & $2(0.95)$ \\
Total & $156(100)$ & $210(100)$ \\
Mean $(\mathrm{m} \pm \mathrm{SD})$ & $12.08 \pm 8.42$ & $17.16 \pm 11.80$ \\
\hline \hline
\end{tabular}

\section{Other Descriptive Statistics of Behavioral and Structural Factors}

Table III presents statistics of behavioral and structural factors that were potential predictors of HIV exposure risk. Everyday discrimination due to racial background was considered a structural factor. We found that more than half of the men in Windsor, $(64.14 \%, \mathrm{n}=100) \mathrm{i}$ and Ottawa, $(54.29 \%, \mathrm{n}=114)$ had experienced $1-5$ types of everyday racism in the year preceding the survey. In Windsor, $14.74 \%$ $(n=23)$, and $9.6 \%(n=15)$ experienced one and two types of everyday racism, respectively. In Ottawa, $10.00 \%(\mathrm{n}=21)$, and $11.90 \% \quad(n=25)$ experienced one and two types of everyday racism, respectively. Precisely, $10.90 \%(n=17)$ and $15.38 \%(n=24)$ experienced 3 and 4 types of everyday racism in the previous year, respectively. While in Ottawa, the respective percentages of men who reported same levels of racism in the same period were $11.90(n=25)$ and $8.57 \%$ $(n=18)$. Men who experienced the maximum (five types) of racism in the preceding year of the study were Windsor, 
$13.46 \%(\mathrm{n}=21)$ and Ottawa, $10.00 \%(\mathrm{n}=21)$. Average counts of types of racism experienced and their standard deviations were, Windsor, $2.00(\mathrm{SD}=1.88)$ and Ottawa, $1.65(\mathrm{SD}=$ $1.83)$.

TABLE III: DESCRIPTIVE STATISTICS OF STRUCTURAL AND BEHAVIORAL CHARACTERISTICS

\begin{tabular}{|c|c|c|}
\hline Characteristics & Windsor $\mathrm{n}(\%)$ & Ottawa n (\%) \\
\hline \multicolumn{3}{|l|}{$\begin{array}{l}\text { Racism: counts of types } \\
\text { experienced }\end{array}$} \\
\hline None & $56(35.90)$ & $96(45.71)$ \\
\hline One & $23(14.74)$ & $21(10.00)$ \\
\hline Two & $15(9.62)$ & $25(11.90)$ \\
\hline Three & $17(10.90)$ & $18(8.57)$ \\
\hline Four & $24(15.38)$ & $29(13.81)$ \\
\hline Five & $21(13.46)$ & $21(10.00)$ \\
\hline $\begin{array}{l}\text { Sub-total: men who experienced } \\
\text { racism }\end{array}$ & $100(64.10)$ & $114(54.29)$ \\
\hline Total valid responses & $156(100)$ & $210(100)$ \\
\hline $\begin{array}{l}\text { Pro-Black community attitude } \\
\text { score }(\mathrm{m} \pm \mathrm{SD})\end{array}$ & $16.08 \pm 3.16$ & $16.28 \pm 3.97$ \\
\hline New masculinity score & $31.57 \pm 5.59$ & $31.58 \pm 5.59$ \\
\hline $\begin{array}{l}\text { Traditional Masculinity score (m } \\
\pm \text { SD) }\end{array}$ & $32.64 \pm 5.07$ & $31.57 \pm 5.63$ \\
\hline Resilience score $(\mathrm{m} \pm \mathrm{SD})$ & $56.88 \pm 8.68$ & $57.31 \pm 8.54$ \\
\hline Condom attitudes score $(\mathrm{m} \pm \mathrm{SD})$ & $27.16 \pm 6.04$ & $26.17 \pm 5.84$ \\
\hline \multicolumn{3}{|l|}{ Health status: self-rating } \\
\hline Excellent & $49(32.89)$ & $67(33.84)$ \\
\hline Very good & $48(32.21)$ & $82(41.41)$ \\
\hline Good & $32(21.48)$ & $37(18.69)$ \\
\hline Fair & $16(10.74)$ & $7(3.54)$ \\
\hline Poor & $1(0.67)$ & $0(0.00)$ \\
\hline Did not know & $1(0.67)$ & $0(0.00)$ \\
\hline Preferred not to answer & $2(1.34)$ & $5(2.53)$ \\
\hline $\begin{array}{l}\text { Sub-total: men who reported } \\
\text { sound health }\end{array}$ & $113(75.84)$ & $186(93.94)$ \\
\hline Total valid responses & $149(100)$ & $198(100)$ \\
\hline
\end{tabular}

Mean scores of pro-Black community attitude in Windsor $(16.08 \pm 3.16)$ and Ottawa $(16.28 \pm 3.97)$ were approximately equal. Similarly, average scores and standard deviations of new masculinity in Windsor relative to Ottawa were approximately equal with values of were $31.57(\mathrm{SD}=5.56)$ and 31.58 ( $\mathrm{SD}=5.59)$, respectively. Means of traditional masculinity scores were $32.64(\mathrm{SD}=5.07)$ and $31.57(\mathrm{SD}=$
$5.63)$ in Windsor and Ottawa, respectively. Mean scores on the resilience scale were $56.88(\mathrm{SD}=8.68)$ and $57.31(\mathrm{SD}=$ 8.54) in Windsor and Ottawa, respectively. Men who selfrated their health status as "excellent" were Windsor, 32.89\% $(n=49)$ and Ottawa, 33.84\% $(n=67)$. Those who rate their health as "very good" were Windsor, $32.21 \quad(\mathrm{n}=48)$ and Ottawa, 41.41\% $(n=82)$. Average scores on the condom attitudes scale were $27.16(\mathrm{SD}=6.04)$ in Windsor and 26.17 $(\mathrm{SD}=5.84)$ in Ottawa.

\section{Test for the Effect of Multilevel (City-level) Factors on HIV Exposure Risk among ACB Men in Windsor and Ottawa, Ontario}

Table IV shows the results of multilevel analysis with the inclusion of city of the residence as the subject of covariance. Estimate of the intercept $15.9(\mathrm{p}<0.01)$ was statistically significant showing within city variation in HIV risk Residual estimate $154.6 \quad(\mathrm{p}<0.001)$ was statistically significant indicating that there are factors of variation in HIV risk that were unaccounted for in the model. At level 2 of the analysis, parameter estimate for city of residence $1.5(\mathrm{p}>0.05)$ was not statistically significant. There was no statistically significant inter-city (Windsor versus Ottawa) covariation of the risk of HIV exposure by heterosexual contact.

TABLE IV: RESUlts LINEAR MIXED MODEL TO ESTIMATE CITY-LEVEL EFFECT ON HIV EXPOSURE RISK

\begin{tabular}{|c|c|c|c|c|}
\hline \multirow[t]{2}{*}{ Variables } & \multicolumn{2}{|c|}{$\begin{array}{l}\text { Model 1: Random } \\
\text { Effects }\end{array}$} & \multicolumn{2}{|c|}{$\begin{array}{c}\text { Model 2: Random } \\
\text { Effects }\end{array}$} \\
\hline & Estimate & $95 \% \mathrm{CI}$ & Estimate & $95 \% \mathrm{CI}$ \\
\hline Intercept & $\begin{array}{c}15.9 * * \\
(1.2)\end{array}$ & $10.6 / 21.3$ & & \\
\hline Residual & & & $\begin{array}{c}154.6 * * * \\
(14.7)\end{array}$ & $128.3 / 186.2$ \\
\hline $\begin{array}{c}\text { Subject (City } \\
{[\text { Windsor }=1 \text {, }} \\
\text { Ottawa }=0] \text { ) }\end{array}$ & & & $1.5(3.0)$ & $<0.1 / 68.0$ \\
\hline
\end{tabular}

$* * * \mathrm{p}<.001, * * \mathrm{p}<.01, * \mathrm{p}<.05$.

E. Factors of HIV Exposure Risk: Result of Hierarchical Linear Model (HLM)

TABLE V: OUTPUTS OF HIERARCHICAL LINEAR REGRESSION ANALYSIS TO PREDICT HIV RISK

\begin{tabular}{|c|c|c|c|c|}
\hline \multirow{2}{*}{ Variables } & \multicolumn{2}{|c|}{ Model 1} & \multicolumn{2}{|c|}{ Model 2} \\
\hline & $B$ & $95 \% \mathrm{CI}$ & $B$ & $95 \% \mathrm{CI}$ \\
\hline \multicolumn{5}{|l|}{ Age categories } \\
\hline $15-29$ years $=1$, otherwise $=0$ & $2.93(2.80)$ & $-2.59 / 8.45$ & $6.09 *(2.70)$ & $.76 / 11.43$ \\
\hline $30-39$ years $=1$, otherwise $=0$ & $3.68(2.73)$ & $-1.70 / 9.07$ & $4.98(2.63)$ & $-.21 / 10.17$ \\
\hline $40-49$ years $=1$, otherwise $=0$ & $3.91(2.73)$ & $-1.46 / 9.27$ & $5.43 *(2.59)$ & $.32 / 10.53$ \\
\hline Marital status (married $=1$, otherwise $=0$ ) & $-3.78(2.12)$ & $-7.97 / .41$ & $-4.03 *(1.98)$ & $-7.94 /-.13$ \\
\hline Education $($ completed high school or tertiary education $=1$, otherwise $=0$ ) & $-1.89(1.67)$ & $-5.18 / 1.41$ & $1.30(1.66)$ & $-1.97 / 4.57$ \\
\hline Employment $($ Employed full time $=1$, Otherwise $=0)$ & $-3.63 *(1.81)$ & $-7.19 /-.06$ & $-3.47 *(1.73)$ & $-6.88 /-.05$ \\
\hline Religion $($ Christianity $=1$, otherwise $=0$ ) & $-2.351 .93)$ & $-6.15 / 1.45$ & $-2.46(1.79)$ & $-5.99 / 1.06$ \\
\hline Racism (counts, types experienced) & & & $.27(0.41)$ & $-.55 / 1.09$ \\
\hline Pro-Black community attitude (score) & & & $.19(0.26)$ & $-.33 / .70$ \\
\hline New masculinity (score) & & & $-.24(0.19)$ & $-.63 / .14$ \\
\hline Traditional masculinity (score) & & & $.33 *(0.16)$ & $<.01 / .65$ \\
\hline Resilience (score) & & & $.18(0.11)$ & $-.03 / .39$ \\
\hline Condom attitudes (score) & & & $.75 * * *(0.13)$ & $.48 / 1.01$ \\
\hline Self-rated health (rating) & & & $-.74(0.88)$ & $-2.47 / 1.02$ \\
\hline (Constant) & $19.4 * * *(3.37)$ & $12.74 / 26.0$ & $-17.94(10.67)$ & $-39 / 3.11$ \\
\hline \multicolumn{5}{|l|}{ Model Summary } \\
\hline$R^{2}$ & & 0.11 & & 0.29 \\
\hline$F$ & & $3.11 * *$ & & $9.14 * * *$ \\
\hline$\Delta R^{2}$ & & - & & 0.18 \\
\hline$\Delta F$ & & - & & $6.02 * *$ \\
\hline
\end{tabular}

\footnotetext{
$* * * \mathrm{p}<.001, * * \mathrm{p}<.01, * \mathrm{p}<.05$
} 
Table $\mathrm{V}$ show the result of HLM to determine HIV risk factors. The model separates the joint effect of demographic variables from the aggregate effect of behavioral and structural factors on risk of HIV exposure via heterosexual contact. All the variables in the models contributed to $29 \%$ $(\mathrm{R} 2=0.29, \mathrm{~F}=9.14, \mathrm{p}<0.001)$ of variation in HIV exposure risk via heterosexual contact. Of this, demographic variables jointly accounted for $11 \%(\mathrm{R} 2=0.29, \mathrm{~F}=3.11, \mathrm{p}<0.01)$ of the variation, while behavioral and structural factors mutually contributed $18 \%(\Delta \mathrm{R} 2=0.18, \Delta \mathrm{F}=6.02, \mathrm{p}<0.01)$ to variation HIV exposure risk through heterosexual contacts among the ACB men.

Based on the results from the final model of the HLM (Table V, model 2) 6 of the 14 variables included in the analysis had statistically significant independent association with HIV exposure risk by heterosexual contacts. Among the demographic factors, age categories 15-29 years $(\beta=6.09$, $\mathrm{p}<0.05, \mathrm{CI}=0.76 / 11.43)$ and 40-49years $(\beta=5.43, \mathrm{p}<0.05$, $\mathrm{CI}=0.32 / 10.53) \quad$ were independently associated with increased exposure risk. In contrast, being in a marriage relationship $\quad(\beta=-4.03, \quad \mathrm{p}<0.05, \quad \mathrm{CI}=-7.94 /-0.13) \quad$ was associated with reduced HIV exposure risk via heterosexual contacts. Similarly, being in a full-time employment $(\beta=-3.47, \quad p<0.05, \quad C I=-6.88 /-0.05) \quad$ was associated with reduced HIV exposure risk. Traditional masculine ideology $(\beta=0.33, \quad \mathrm{p}<0.05, \quad \mathrm{CI}=<0.01 / 0.65) \quad$ was associated with increased HIV exposure risk by heterosexual contact. Also, negative attitudes toward condom use $(\beta=0.33, p<0.05$, $\mathrm{CI}=<0.01 / 0.65)$ was associated with increased HIV exposure risk via heterosexual contact.

\section{DISCUSSION}

Results of this study show that HIV risk among heterosexual ACB men is associated with demographic, behavioral and structural factors. Although city-level effects were not found, HIV risk had a joint and independent associations with the structural and behavioral factors included the model of analysis. Moreover, the demographic factors associated jointly and independently with HIV risk. Discussion of each statistically significant independent association are provided in this section.

\section{A. Age Categories}

Age category 15-29 years was associated with increased HIV exposure risk. This is not surprising because HIV surveillance statistics showed that between 2014 and 2018, males aged 20-29 years old experienced the highest increase in HIV diagnosis rates in Canada; and prevalence statistics in males showed that youth aged 20 -29years accounted for the second highest percent of new cases (24.8\%) (PHAC, 2019). A comparable survey in the US showed that youth aged 13 24 years made up $21 \%$ of new cases of HIV in 2018 (CDC, 2018). This is perhaps the case for young men in this age category in because sexual experimentation common among in this age class [42], [43], alongside drug abuse motivated by peer pressure and complacent attitudes towards HIV risks accentuated by generational changes in HIV epidemic [44]. While these statistics is troubling, the situation is worse for $\mathrm{ACB}$ heterosexual men in this age category because the ACB community is already disproportionately affected by HIV due to factors highlighted earlier on.

Also, ACB men aged 40-49 years had increased risk of HIV exposure through heterosexual contact. Statistics from 2014 to 2018 consistently show similar trend in the emergence of new cases of HIV between persons aged 40 49years and those aged 20-29 years. In contrast to persons aged 15-29 years, experimentation sex and drug may not be the reasons for increased HIV exposure among Black men aged 40-49years, but several other factors interplay to increase exposure risk among this group. Systemic factors such as socially ascribed traditional masculine identity, unemployment, underemployment, loss of marriage risky may present non-romantic sexual relationship, and consequently risk behaviours as coping mechanisms.

\section{B. Marital Status}

Our findings showed that being married was negatively correlated with HIV exposure risk. Several related studies have shown that marital status is an important indicator of HIV risk. For example, a study of Black Africans showed that the odds of HIV infection were twice higher among adults who were never married relative to those who were married [45]. Also, the US National mortality Survey showed that marital status was associated with HIV related mortality among men, and single persons were 13 times more likely to die from HIV than married persons. However, several other factors such as the quality and duration of the marriage can compound the impact of being married in reducing HIV risk. For example, The US survey also showed that the odds of HIV related mortality were 4.3 times higher among the divorced and separated persons than in those who were still in marriage relationship (source). Similarly, another study found that the odds of HIV infection was lower among married individuals who were still living with their spouse compared to all other marital status groups [46]. In terms of marriage duration, a study found that HIV Risk reduced with number of years spent in a marriage relationship [47].

\section{Employment}

Reduced HIV exposure risk was also linked to full-time employment. Conversely, this implied that unemployment or underemployment may increase exposure risk among heterosexual ACB men. Literature suggests that unemployment is an HIV risk factor. For example, limited economic opportunities have been associated with riskier health behaviors such as substance use [48], exchanging sex for money [49] power differences in sexual relationship [50] all of which ultimately leads to risks of HIV infection. Hence poverty and income inequality urban areas have been associated with HIV prevalence rates [51]. This corroborates the result of our analysis as poverty and income inequality are often linked with high unemployment rates and imbalance in employment distribution, respectively. Among those already living with the Virus, studies have also shown that unemployment is strongly associated with HIV related mortality [52], [53]. Employment status transcends individual level to a systemic level factor if for example, unemployment or underemployment situation is not within the individual's control. Hence, tackling the situation from both individual and systemic point view may be most effective. 


\section{Traditional Masculinity}

We found that ACB men with traditional masculine ideology associated with increased risk of HIV exposure via heterosexual contact. Traditional masculinity may be viewed as a social construct that defines some Black, hence it can be seen from two perspectives, as an individual level factor as well as a systemic factor because although it is an individual attributes, it is socially ascribed. Traditional masculinity describes traditional attitudes towards men about their expected roles and responsibilities [54], [55]. These societal attitudes towards men impact many areas of men's life including their sexual decisions and behaviors. In assumption of the socially prescribed masculinity, some Black men set aside their desires and concerns to meet the peer and societal expectations of their sexuality [56]. Increased HIV exposure risk, may be informed by the social perception of Black men as hyper masculine, which lure many of them to unprotected and multiple sex partnerships [57]-[59]. A similar study associated multiple sexual partnerships, cross-generational sex, sexual violence against women, non-use of condoms, and low level of HIV awareness have been associated with traditional masculinity [60]. Thus, studies suggest reconstructing masculine ideology via culturally sensitive interventions to reduce sexual adventure or multiple partners [61], [62], and consequently reduce HIV exposure risk among ACB men.

\section{E. Condom Attitude}

HIV exposure risk was associated with condom attitude among the heterosexual ACB men. Inferred from the Theory of Reasoned Action [63], risky sexual behavior can be a function of condom attitude, amidst other attitudes, norms, and intentions. Yet, the Theory of Planned Behavior propounds that the individual has control beliefs [64], for example, over whether to engage or not engage in a risky sexual behavior. Research evidence has showed that consistent use of condom reduces the likelihood of HIV transmission per sex act by $95 \%$ and the HIV incidence in sero-discordant couples by $90-95 \%$ per year [65]. A metaanalysis also found that condom use of variable consistency among sero-discordant couples reduced the annual HIV incidence by $69 \%$ [66]. More recent studies have shown that stronger peer condom use norms were associated with a lower frequency of risk behavior [67] and lesser involvement in HIV risk behavior was associated with the perception of social norms that support condom use [15]. Hence, positive attitude as opposed to negative attitude towards condom use implementable by the logic of the theory of planned behavior is an important factor in reducing HIV exposure risk.

\section{CONCLUSION}

HIV exposure risk among ACB men in Windsor and Ottawa are a function of intersecting demographic, behavioral, and structural factors. Condom attitude, traditional masculine ideology and belonging to age categories 15-29 years and 40-49years were implicated for increased risk of HIV exposure, while marriage and full-time employment reduced the risk of exposure. Hence, we recommend continued promotion of condom use as an important HIV prevention strategy, while widespread use of
PrEP and PEP will effective alternatives. Moreover, community leaders, including those of faith-based organisations in the ACB communities have significant roles in reducing HIV vulnerability through increased marriage seminars and counselling for potential couples, especially young intending couples who may still be experimenting with sex and for older men having troubled marriage relationships. Traditionally biased view towards promotion of condom use should be avoided in case new persons who may be lured into infidelity for any reason. Policy to promote equity in employment and increase the share of ACB populations in full-time employment an effective means of reducing risky sexual behavior and the spread of HIV. Finally, the role of various stakeholders in easing access to health care in the ACB community will reduce HIV risks. For example, behavioral change in favour of consistent use of condom is realizable where the healthcare providers are easily accessible to provide the relevant counselling.

\section{DECLARATIONS}

\section{A. Funding}

This work was supported by the [Ontario HIV Treatment Network] under Grant [\#334717]

\section{B. Conflicts of Interest}

The authors declare no conflict of interests.

\section{Ethics Approval}

Ethics approval and consent to participate. The study was approved by Ethics review Board at Ryerson University (REB \#2015-118), University of Ottawa (Certificate \# H0615-23) University of Toronto (Protocol \#31973), University of Windsor (REB \#32485) York University (REB \# 2015217), and University of Louisville (REB \#15.0453).

\section{Consent to participate}

Informed consent was obtained from all individual participants included in the study.

\section{E. Availability of Data and Material}

Data analysis is still in progress and will be uploaded to a data repository in due course. To access the study data, contact the weSpeak Program nominated Principal Investigator by email at: jph.wong@ryerson.ca

\section{F. Authors' Contributions}

FIO and EBE led conceptualization and design of this paper. FIO, JE and JK led data acquisition; EBE led data analysis and first draft, FIO \& JE supervised the manuscript development. All authors (FIO, EBE, JK, BG and JE) contributed to data analysis and interpretation, literature review and initial draft of the manuscript. All authors contributed substantially to critical review for important intellectual contributions. All authors contributed to and approved the final version for publication. 


\section{REFERENCES}

[1] “The Epidemiology of HIV in Canada." https://www.catie.ca/en/factsheets/epidemiology/epidemiology-hiv-canada (accessed Jan. 06, 2021).

[2] E. Maticka-Tyndale, J. Kerr, and R. Mihan, "A profile of the sexual experiences of African, Caribbean and Black Canadian youth in the context of Canadian youth sexuality," Can. J. Hum. Sex., vol. 25, no. 1, pp. 41-52, Feb. 2016, doi: 10.3138/cjhs.251-A1.

[3] M.-C. Boily, M. Alary, and R. F. Baggaley, "Neglected issues and hypotheses regarding the impact of sexual concurrency on HIV and sexually transmitted infections," AIDS Behav., vol. 16, no. 2, pp. 304 311, Feb. 2012, doi: 10.1007/s10461-011-9887-0.

[4] O. Dosekun and J. Fox, "An overview of the relative risks of different sexual behaviours on HIV transmission," Curr. Opin. HIV AIDS, vol. 5, no. 4, pp. 291-297, Jul. 2010, doi: 10.1097/COH.0b013e32833a88a3.

[5] J. Kerr, T. Northington, T. Sockdjou, and E. Maticka-Tyndale, "Perceived Neighborhood Quality and HIV-related Stigma among African Diasporic Youth; Results from the African, Caribbean, and Black Youth (ACBY) Study," J. Health Care Poor Underserved, vol. 29, no. 2, pp. 651-663, 2018, doi: 10.1353/hpu.2018.0049.

[6] Centre for Infectious Disease Prevention and Control (Canada) and Public Health Agency of Canada, HIV transmission risk: a summary of the evidence. Ottawa, Ont.: Public Health Agency of Canada, 2013.

[7] M. S. Cohen and C. D. Pilcher, "Amplified HIV transmission and new approaches to HIV prevention," J. Infect. Dis., vol. 191, no. 9, pp. 13911393, May 2005, doi: 10.1086/429414.

[8] D. P. Wilson, M. G. Law, A. E. Grulich, D. A. Cooper, and J. M. Kaldor, "Relation between HIV viral load and infectiousness: a model-based analysis," Lancet Lond. Engl., vol. 372, no. 9635, pp. 314-320, Jul. 2008, doi: 10.1016/S0140-6736(08)61115-0.

[9] M.-C. Boily et al., "Heterosexual risk of HIV-1 infection per sexual act: systematic review and meta-analysis of observational studies," Lancet Infect. Dis., vol. 9, no. 2, pp. 118-129, Feb. 2009, doi: 10.1016/S14733099(09)70021-0.

[10] T. C. Quinn et al., "Viral load and heterosexual transmission of human immunodeficiency virus type 1. Rakai Project Study Group,” N. Engl. J. Med., vol. 342, no. 13, pp. 921-929, Mar. 2000, doi: 10.1056/NEJM200003303421303.

[11] P. Patel, C. B. Borkowf, J. T. Brooks, A. Lasry, A. Lansky, and J. Mermin, "Estimating per-act HIV transmission risk: a systematic review," AIDS, vol. 28, no. 10, pp. 1509-1519, Jun. 2014, doi: 10.1097/QAD.0000000000000298.

[12] P. H. A. of Canada, "HIV Surveillance report, 2018, CCDR 45(12)," aem, Dec. 06, 2019. https://www.canada.ca/en/publichealth/services/reports-publications/canada-communicable-diseasereport-ccdr/monthly-issue/2019-45/issue-12-december-5-2019/article1-2018-hiv-survellance-report.html (accessed Jan. 06, 2021).

[13] D. P. Kennedy, R. A. Brown, D. Golinelli, S. L. Wenzel, J. S. Tucker, and S. R. Wertheimer, "Masculinity and HIV Risk among Homeless Men in Los Angeles,' Psychol. Men Masculinity, vol. 14, no. 2, pp. 156 167, 2013, doi: 10.1037/a0027570.

[14] E. J. Silver and L. J. Bauman, "Association of 'Macho Man' Sexual Attitudes and Behavioral Risks in Urban Adolescents," Am. J. Sex. Educ., vol. 9, no. 2, pp. 176-187, Apr. 2014, doi: 10.1080/15546128.2014.900466.

[15] J. L. Peterson, R. Rothenberg, J. M. Kraft, C. Beeker, and R. Trotter, "Perceived condom norms and HIV risks among social and sexual networks of young African American men who have sex with men," Health Educ. Res., vol. 24, no. 1, pp. 119-127, Feb. 2009, doi: 10.1093/her/cyn003.

[16] "HIV Transmission | HIV Basics | HIV/AIDS | CDC," Oct. 28, 2020 https://www.cdc.gov/hiv/basics/transmission.html (accessed Jan. 06, 2021).

[17] R. M. Anderson, R. M. May, M. C. Boily, G. P. Garnett, and J. T. Rowley, "The spread of HIV-1 in Africa: sexual contact patterns and the predicted demographic impact of AIDS," Nature, vol. 352, no. 6336, pp. 581-589, Aug. 1991, doi: 10.1038/352581a0.

[18] H. R. Barrett and B. Mulugeta, "Human Immunodeficiency Virus (HIV) and migrant 'risk environments': the case of the Ethiopian and Eritrean immigrant community in the West Midlands of the UK," Psychol. Health Med., vol. 15, no. 3, pp. 357-369, May 2010, doi: $10.1080 / 13548501003653192$.

[19] J. R. Hargreaves et al., "Systematic review exploring time trends in the association between educational attainment and risk of HIV infection in sub-Saharan Africa," AIDS Lond. Engl., vol. 22, no. 3, pp. 403-414, Jan. 2008, doi: 10.1097/QAD.0b013e3282f2aac3.

[20] W. M. Msisha, S. H. Kapiga, F. Earls, and S. V. Subramanian, "Socioeconomic status and HIV seroprevalence in Tanzania: a counterintuitive relationship," Int. J. Epidemiol., vol. 37, no. 6, pp. 1297-1303, Dec. 2008, doi: 10.1093/ije/dyn186.

[21] R. Vivancos, I. Abubakar, and P. R. Hunter, "Foreign travel, casual sex, and sexually transmitted infections: systematic review and metaanalysis,” Int. J. Infect. Dis. IJID Off. Publ. Int. Soc. Infect. Dis., vol. 14, no. 10, pp. e842-851, Oct. 2010, doi: 10.1016/j.ijid.2010.02.2251.

[22] S. Baidoobonso, G. R. Bauer, K. N. Speechley, E. Lawson, and BLACCH Study Team, "HIV risk perception and distribution of HIV risk among African, Caribbean and other Black people in a Canadian city: mixed methods results from the BLACCH study," BMC Public Health, vol. 13, p. 184, Mar. 2013, doi: 10.1186/1471-2458-13-184.

[23] I. Konkor, "HIV vulnerabilities among heterosexual African, Caribbean and other Black men in London, Ontario," Electron. Thesis Diss. Repos., Jun. 2019, [Online]. Available: https://ir.lib.uwo.ca/etd/6243.

[24] R. P. Kerani et al., "Evidence of Local HIV Transmission in the African Community of King County, Washington," J. Immigr. Minor. Health, vol. 19, no. 4, pp. 891-896, Aug. 2017, doi: 10.1007/s10903-016-04583.

[25] J. Ross, C. O. Cunningham, and D. B. Hanna, "HIV outcomes among migrants from low-income and middle-income countries living in highincome countries: a review of recent evidence," Curr. Opin. Infect. Dis., vol. 31, no. 1, pp. 25-32, Feb. 2018, doi: 10.1097/QCO.0000000000000415.

[26] F. Omorodion, K. Gbadebo, and P. Ishak, "HIV vulnerability and sexual risk among African youth in Windsor, Canada," Cult. Health Sex., vol. 9, no. 4, pp. 429-437, Aug. 2007, doi: 10.1080/13691050701256721.

[27] C. Magazine, "Sexual Behavior and Attitudes among White, Black, Latinx, and Asian College Students - Contexts." https://contexts.org/blog/sexual-attitudes-among-college-studentssimilarities-between-white-black-latinx-and-asian-students/ (accessed Jan. 06, 2021).

[28] "Community-level influences of behavior change," OUPblog, Jan. 02, 2013. https://blog.oup.com/2013/01/community-level-influences-ofbehavior-change/ (accessed Jan. 06, 2021).

[29] E. Reed, M. C. Santana, L. Bowleg, S. L. Welles, C. R. Horsburgh, and A. Raj, "Experiences of racial discrimination and relation to sexual risk for HIV among a sample of urban black and African American men," J. Urban Health Bull. N. Y. Acad. Med., vol. 90, no. 2, pp. 314-322, Apr. 2013, doi: 10.1007/s11524-012-9690-X.

[30] N. Madise, E. Zulu, and J. Ciera, "Is poverty a driver for risky sexual behaviour? Evidence from national surveys of adolescents in four African countries," Afr. J. Reprod. Health, vol. 11, no. 3, pp. 83-98, Dec. 2007.

[31] V. Agadjanian, C. Arnaldo, and B. Cau, "Health Costs of Wealth Gains: Labor Migration and Perceptions of HIV/AIDS Risks in Mozambique," Soc. Forces Sci. Medium Soc. Study Interpret., vol. 89, no. 4, pp. 1097 1117, Jun. 2011, doi: 10.1093/sf/89.4.1097.

[32] K. Awusabo-Asare and S. K. Annim, "Wealth status and risky sexual behaviour in Ghana and Kenya," Appl. Health Econ. Health Policy., vol 6, no. 1, pp. 27-39, 2008, doi: 10.2165/00148365-200806010-00003.

[33] CDC, National Center for HIV/AIDS, Viral Hepatitis, STD, and TB Prevention Division of HIV/AIDS Prevention., "Deaths among persons with AIDS through December 2000.” 2002, Accessed: Apr. 14, 2021 [Online].

[34] J. A. Bauermeister, L. Eaton, J. Andrzejewski, J. Loveluck, W. VanHemert, and E. S. Pingel, "Where You Live Matters: Structural Correlates of HIV Risk Behavior Among Young Men Who Have Sex with Men in Metro Detroit," AIDS Behav., vol. 19, no. 12, pp. 2358 2369, Dec. 2015, doi: 10.1007/s10461-015-1180-1.

[35] I. Konkor et al., "An Intersectional Approach to HIV Vulnerabilities and Testing Among Heterosexual African Caribbean and Black Men in London, Ontario: Results From the weSpeak Study," J. Racial Ethn. Health Disparities, vol. 7, Mar. 2020, doi: 10.1007/s40615-020-007373.

[36] D. R. Williams, null Yan Yu, J. S. Jackson, and N. B. Anderson, "Racial Differences in Physical and Mental Health: Socio-economic Status, Stress and Discrimination," J. Health Psychol., vol. 2, no. 3, pp. 335351, Jul. 1997, doi: 10.1177/135910539700200305.

[37] W. P. Hammond, D. Matthews, D. Mohottige, A. Agyemang, and G. Corbie-Smith, "Masculinity, medical mistrust, and preventive health services delays among community-dwelling African-American men," J. Gen. Intern. Med., vol. 25, no. 12, pp. 1300-1308, Dec. 2010, doi 10.1007/s11606-010-1481-z.

[38] M. P. Carey and K. E. E. Schroder, "Development and Psychometric Evaluation of the Brief HIV Knowledge Questionnaire," AIDS Educ. Prev. Off. Publ. Int. Soc. AIDS Educ., vol. 14, no. 2, pp. 172-182, Apr. 2002.

[39] K. E. Baruth and J. J. Caroll, “A formal assessment of resilience: The Baruth Protective Factors Inventory,” J. Individ. Psychol., vol. 58, no. 3, pp. 235-244, 2002. 
[40] O. Friborg, O. Hjemdal, J. H. Rosenvinge, and M. Martinussen, “A new rating scale for adult resilience: what are the central protective resources behind healthy adjustment?" Int. J. Methods Psychiatr. Res., vol. 12, no. 2, pp. 65-76, 2003, doi: 10.1002/mpr.143.

[41] T. Roy, C. Anderson, C. Evans, M. S. Rahman, and M. Rahman, "Crosscultural adaptation of the short-form condom attitude scale: validity assessment in a sub-sample of rural-to-urban migrant workers in Bangladesh,” BMC Public Health, vol. 13, no. 1, p. 240, Mar. 2013, doi: 10.1186/1471-2458-13-240.

[42] C. M. Grello, D. P. Welsh, and M. S. Harper, "No Strings Attached: The Nature of Casual Sex in College Students," J. Sex Res., vol. 43, no. 3, pp. 255-267, 2006.

[43] Omorodion, F. I., Etowa, E.B., Kerr, J., Ghose, B., and Etowa, J., "Correlates of Casual Sex Amidst Vulnerability to HIV Among ACB Heterosexual Men in Ottawa and Windsor, Ontario Canada," J. Racial Ethn. Health Disparities, 2021, doi: 10.1007/s40615-021-00975-z.

[44] National Institute on Drug Abuse (NIDA), Who Is at Risk for HIV Infection and Which Populations Are Most Affected?. 2020.

[45] B. Tlou, "The influence of marital status on HIV infection in an HIV hyperendemic area of rural South Africa, 2000-2017," Afr. J. AIDS Res. AJAR, vol. 18, no. 1, pp. 65-71, Mar. 2019, doi: 10.2989/16085906.2018.1559209.

[46] O. Shisana et al., "Does marital status matter in an HIV hyperendemic country? Findings from the 2012 South African National HIV Prevalence, Incidence and Behaviour Survey," AIDS Care, vol. 28, no. 2, pp. 234-241, Feb. 2016, doi: 10.1080/09540121.2015.1080790.

[47] A. M. Nabukenya, A. Nambuusi, and J. K. B. Matovu, "Risk factors for HIV infection among married couples in Rakai, Uganda: a crosssectional study," BMC Infect. Dis., vol. 20, no. 1, p. 198, Mar. 2020, doi: 10.1186/s12879-020-4924-0.

[48] J. A. Pellowski, S. C. Kalichman, K. A. Matthews, and N. Adler, "A pandemic of the poor: social disadvantage and the U.S. HIV epidemic,' Am. Psychol., vol. 68, no. 4, pp. 197-209, 2013, doi: 10.1037/a0032694.

[49] E. D. Riley, M. Gandhi, C. Hare, J. Cohen, and S. Hwang, "Poverty, unstable housing, and HIV infection among women living in the United States," Curr. HIV/AIDS Rep., vol. 4, no. 4, pp. 181-186, Dec. 2007 , doi: 10.1007/s11904-007-0026-5.

[50] S. C. Kalichman et al., "Food insufficiency and medication adherence among people living with HIV/AIDS in urban and peri-urban settings," Prev. Sci. Off. J. Soc. Prev. Res., vol. 12, no. 3, pp. 324-332, Sep. 2011, doi: 10.1007/s11121-011-0222-9.

[51] M.-L. G. Buot et al., "Beyond Race and Place: Distal Sociological Determinants of HIV Disparities," PLOS ONE, vol. 9, no. 4, p. e91711, Apr. 2014, doi: 10.1371/journal.pone.0091711.

[52] M. Maruthappu, C. Zhou, C. Williams, T. Zeltner, and R. Atun, "Unemployment and HIV mortality in the countries of the Organisation for Economic Co-operation and Development: 1981-2009," JRSM Open, vol. 8, no. 7, Jul. 2017, doi: 10.1177/2054270416685206.

[53] D. Paraskevis et al., "HIV-1 outbreak among injecting drug users in Greece, 2011: a preliminary report," Euro Surveill. Bull. Eur. Sur Mal. Transm. Eur. Commun. Dis. Bull., vol. 16, no. 36, Sep. 2011, doi: 10.2807/ese.16.36.19962-en.

[54] A. B. Nguyen, T. T. Clark, K. B. Hood, M. A. Corneille, A. Y. Fitzgerald, and F. Z. Belgrave, "Beyond traditional gender roles and identity: does reconceptualisation better predict condom-related outcomes for African-American women?," Cult. Health Sex., vol. 12, no. 6, pp. 603-617, Aug. 2010, doi: 10.1080/13691051003658127.

[55] N. F. Sanchez, J. P. Sanchez, and A. Danoff, "Health Care Utilization, Barriers to Care, and Hormone Usage Among Male-to-Female Transgender Persons in New York City," Am. J. Public Health, vol. 99, no. 4, pp. 713-719, Apr. 2009, doi: 10.2105/AJPH.2007.132035.

[56] S. Baidoobonso, G. R. Bauer, K. N. Speechley, E. Lawson, and BLACCH Study Team, "Social and Proximate Determinants of the Frequency of Condom Use Among African, Caribbean, and Other Black People in a Canadian City: Results from the BLACCH Study," J. Immigr. Minor. Health, vol. 18, no. 1, pp. 67-85, Feb. 2016, doi: 10.1007/s10903-014-9984-Z.

[57] L. Bowleg, M. Teti, D. J. Malebranche, and J. M. Tschann, “'It's an Uphill Battle Everyday': Intersectionality, Low-Income Black Heterosexual Men, and Implications for HIV Prevention Research and Interventions," Psychol. Men Masculinity, vol. 14, no. 1, pp. 25-34, Jan. 2013, doi: 10.1037/a0028392.

[58] L. F. O'Sullivan, S. Hoffman, A. Harrison, and C. Dolezal, “Men, Multiple Sexual Partners, and Young Adults' Sexual Relationships: Understanding the Role of Gender in the Study of Risk," J. Urban Health Bull. N. Y. Acad. Med., vol. 83, no. 4, pp. 695-708, Jul. 2006, doi: 10.1007/s1 1524-006-9062-5.

[59] J. K. Ganle, "Hegemonic Masculinity, HIV/AIDS Risk Perception, and Sexual Behavior Change Among Young People in Ghana,' Qual. Health
Res., vol. 26, no. 6, pp. 763-781, May 2016, doi: 10.1177/1049732315573204.

[60] Barker, D. and Ricardo, C., "Young Men and the Construction of Masculinity in Sub-Saharan Africa: Implications for HIV/AIDS, Conflict, and Violence." The World Bank, 2005, Accessed: Feb. 03, 2021. [Online]. Available: https://promundoglobal.org/wpcontent/uploads/2015/01/Young-Men-and-the-Construction-ofMasculinity-in-Sub-Saharan-Africa-Implications-for-HIV-AIDSConflict-and-Violence.pdf.

[61] L. Bowleg, "When Black + Lesbian + Woman $\neq$ Black Lesbian Woman: The Methodological Challenges of Qualitative and Quantitative Intersectionality Research," Sex Roles, vol. 59, no. 5, pp. 312-325, Sep. 2008, doi: 10.1007/s11199-008-9400-z.

[62] M. Corneille, J. E. Fife, F. Z. Belgrave, and B. C. Sims, "Ethnic identity, masculinity, and healthy sexual relationships among African American men," Psychol. Men Masculinity, vol. 13, no. 4, pp. 393-399, 2012, doi: $10.1037 / \mathrm{a} 0026878$.

[63] Fishbein, M. and Ajzen, I., Understanding Attitudes and Predicting Social Behavior. Englewood Cliffs, N.J.; Prentice Hall, 1980.

[64] I. Ajzen, "The theory of planned behavior," Organ. Behav. Hum. Decis. Process., vol. 50, no. 2, pp. 179-211, Dec. 1991, doi: 10.1016/07495978(91)90020-T.

[65] S. D. Pinkerton and P. R. Abramson, "Effectiveness of condoms in preventing HIV transmission," Soc. Sci. Med., vol. 44, no. 9, pp. 13031312, May 1997, doi: 10.1016/S0277-9536(96)00258-4.

[66] S. C. Weller, "A meta-analysis of condom effectiveness in reducing sexually transmitted HIV," Soc. Sci. Med. 1982, vol. 36, no. 12, pp. 1635-1644, Jun. 1993, doi: 10.1016/0277-9536(93)90352-5.

[67] G. A. Millett, S. A. Flores, J. L. Peterson, and R. Bakeman, "Explaining disparities in HIV infection among black and white men who have sex with men: a meta-analysis of HIV risk behaviors," AIDS Lond. Engl., vol. 21, no. 15, pp. 2083-2091, Oct. 2007, doi: 10.1097/QAD.0b013e3282e9a64b.

\section{Francisca I. Omorodion, $\mathrm{PhD}$, MA, BA}

Associate Professor, Department of Sociology, Anthropology and Criminology; University of Windsor, Ontario, Canada. Research and Teaching Areas: Sexuality, STIs/HIV in relation to heterosexual Black population, Family, and Human trafficking.

Egbe B. Etowa, PhD, M.Sc. Postdoctoral Fellow, weSpeak Program, Department of Sociology, Anthropology and Criminology; University of Windsor, Ontario, Canada. Research Interests: Welfare and economics of the agrarian sector, Social determinants of health and welfare disparities in Black communities.

Jelani Kerr, PhD, MSPH Associate Professor, Department of Health Promotion and Behavioral Sciences, University of Louisville, Kentucky. His research focuses on HIV vulnerabilities of young people in the African Diaspora in the US and Canada. Specifically, he investigates behavioral and social determinants that influence HIV/AIDS inequities.

Bishwajit Ghose, PhD, MPH Postdoctoral Fellow, School of Nursing, University of Ottawa, Ottawa, Ontario, Canada. His areas of expertise include lifestyle medicine, maternal and child health, geriatric health, health inequality, and universal healthcare in the global South.

Josephine Etowa, PhD, M.N. B.Sc. N. Full Professor, School of Nursing, University of Ottawa, Ontario, Canada. Her research program which is grounded in over twenty-three years of clinical practice is in inequity in health and health care as well as maternal-newborn health. 